\title{
Cyclic Adenosine 3,5-Monophosphate Measurement
}

National Cancer Institute

\section{Source}

National Cancer Institute. Cyclic Adenosine 3,5-Monophosphate Measurement. NCI

Thesaurus. Code C124339.

The determination of the amount of cyclic adenosine 3,5-monophosphate present in a sample. 